\title{
Application of transform software for downscaling global climate model EdGCM results in north-eastern Bangladesh
}

\author{
Fahmida Ishaque, Israt Jahan Ripa ${ }^{\dagger}$, Altaf Hossain, Abdur Rashid Sarker, Gazi Tamiz Uddin, \\ Hafizur Rahman, Joyshankar Baidya \\ Department of Agricultural Construction and Environmental Engineering, Sylhet Agricultural University, Bangladesh
}

\begin{abstract}
Downscaling is a state-of-the-art technique to generate fine-resolution climate change prediction and an obvious tool for forecasting future climate scenarios for many data-scarce areas like Bangladesh. The Educational Global Climate Model (EdGCM) predicts numerically and its performance was not evaluated for Bangladesh earlier. Due to this reason, an attempt has been made to apply a new geostatistical approach with the help of transform software to downscale EdGCM for identifying the trend of surface air temperature at the Sylhet district. Both Doubled $\mathrm{CO}_{2}$ and Global_Warming_01 are simulated from EdGCM and maps are generated to depict global temperature variations. Downscaling is applied to the outputs from Doubled_CO $\mathrm{CO}_{2}$ scenario. Percent of bias (PBIAS), Nash-Sutcliffe efficiency (NSE) and the ratio of root mean square error to the standard deviation of measured data (RSR) values are satisfactory and acceptable. The trend analysis was performed using the Mann-Kendall Trend test and Sen's slope estimator. Temperature changes are significant for both downscaled and observed results of p-value which is less than alpha $=0.05$. Mann-Kendall Z tests for annual downscaled and IPCC during (2006-2020) show a positive trend. Downscaled predicted annual average temperature (simulations by Doubled $\mathrm{CO}_{2}$ ) for 2020 is $21.67^{\circ} \mathrm{C}$ for the Sylhet district.
\end{abstract}

Keywords: Climate, Downscaling, EdGCM, Mann-Kendall Trend test, NSE, Surface air temperature

\section{Introduction}

Climate is defined as the overall weather situations over a specific time-span and a specific area. Temperature is one of the most important parameters in climatic studies and can be taken into consideration the major issue causing climate change [1].

Nowadays Bangladesh faces significant vulnerability due to climate change. The morphological and topological set of Bangladesh creates it prone to climate change impact, thus rising sea level and different climate anomalies such as monsoon transferring and changing rainfall intensity [2]. The north-eastern part of Bangladesh is a significant area with respect to climate change impacts. Because the region is hazard-prone and climate change affect has an unfavorable result on them. Due to locational topography the fluctuation of temperature is much greater here [3]. Computer-driven global climate models (GCMs) are one of the basic tools used now-a-days in climate analysis. But only a few Bangladeshi researchers have access to them, which typically involves running high-computing facilities and skilled programmers [4]. The Educational Global Climate Model (EdGCM) addresses this issue by offering a research-grade GCM within an interactive user-friendly framework that can be run on traditional desktop computers and laptops. NASA and Columbia University have developed it to provide its users access to a real-time global climate model and allow them to understand the details of the climate model setup, model operation, post-processing and scientific visualization. Therefore, an initiative is needed to train the future climatologist to deal with the multitude of climate impacts which will happen over the coming decades [5].

The GCM at the core of EdGCM which are currently uses to check previous, present, and future climates [6]. EdGCM software is an atmosphere-ocean model of 3-dimensions. The model solves five basic physical equations numerically which is the important key feature of the models. The EdGCM has 7,776 atmospheric grid cells that are $8^{\circ}$ latitude by $10^{\circ}$ longitude, consisting of nine vertical layers, two ground layers and two layers of the ocean.
This is an Open Access article distributed under the terms of the Creative Commons Attribution Non-Commercial License (http://creativecommons.org/licenses/by-nc/3.0/) which permits unrestricted non-commercial use, distribution, and reproduction in any medium, provided the original work is properly cited.

Copyright (C) 2021 Korean Society of Environmental Engineers
Received September 17, 2019 Accepted January 06, 2020

${ }^{\dagger}$ Corresponding author

Email: isratsau46@gmail.com

Tel: +8801789069174

ORCID: 0000-0001-9493-4274 
For each grid cell calculations are carried out in fifteen-minute (simulation time) during the simulation period [7]. There are 6 ready-to-run climate model experiments completed by EdGCM: two modern climate simulations, three global warming simulations and one simulation of ice age. High-quality global scale, as well as regional scale and time series plot, can be produced by using EdGCM suite [4].

A study is conducted to assess the predictability efficiency of the EdGCM. Lyapunov exponent (LE) and Supremum Lyapunov exponent (SLE) are chosen to explore the EdGCM predictability to average surface air temperatures in South East Asia. The results recommend the excellent performance of EdGCM because it has the predictability of at least 90 years [8]. A dynamic equation is for surface air temperature from the Educational Global Climate Model (EDGCM) was developed for Southeast Asia. Results of the equation application show that the errors of the proposed equations are less than the errors of EdGCM's direct interpolation [9]. EdGCM model with Doubled_ $\mathrm{CO}_{2}$ and scenario of Modern_PredictedSST (Sea Surface Temperature) was used to forecasting temperature changes in Pakistan. Doubled_ $\mathrm{CO}_{2}$ model predicted overall $11.38 \%$ lower values of temperature than real ones [10]. Global Climate Model (GCM) has been applied to forecasting changes in temperature of Saudi Arabia for two scenarios namely a double carbon dioxide $\left(2 \mathrm{CO}_{2}\right)$ and a Modern_Predicted SST (Sea Surface Temperature) scenario. The overall change in land surface temperature is a $4.72^{\circ} \mathrm{C}$ increase by the end of the 21st century [11].

GCMs exhibit that increasing anthropogenic greenhouse gas forcing will have enormous climate influences on regional and global scales. Due to coarse resolution, the results from GCMs cannot directly apply to precise areas for climate change study. Some "downscaling" methods have been created to overcome the mismatch of scales among coarse resolution GCMs and the local-scale data required to study regional influences. Statistical processes for downscaling climate model (GCM) outputs have been employed over the past decade to evaluate the possible effects on the hydrologic regime and climate change variability. Statistical techniques are required to downscale the results of GCMs to local areas [12].

Downscaling has become a technique of climate research as a result of its capacity to supplied climate data at resolutions that build the result useable for effect studies at regional, sub-regional, local and point scales. Two kinds of downscaling are generally available, both dynamic and statistical. Statistical downscaling is studied extensively due to the applicability of findings for climate change impact. This technique lies in the capability to use the features of the free atmosphere as predictors of the local climate components (which are known as the predicted). Information on the large-scale predictors may be created by the direct weather observation or by some climate model result, but downscaling is essential as a method, due to the usability of climate impact results and dangers assessments [13]. Downscaling has been regarded as a significant component of climate change impact evaluation as GCMs are only accessible at coarse resolution. But most hydrological models need climate change data at a finer resolution [14]. Statistical downscaling techniques $[15,16]$ mainly based on observational records and the model parameters are forecasted from a training set of large-scale and local observations which is used to infer changes in the local variables due to changes in the large-scale fields simulated by GCM sensitivity experiments [17]. A statistical model was used for downscaling the monthly mean temperature. It was constructed from a linear regression model linked with a principal component analysis (PCA) as the preprocessing technique for predictors. For a few stations and in some months, there are some mismatches with findings [18]. Statistical downscaling may provide a more suitable approach for certain climate impact studies than dynamical downscaling, particularly, when station and point values for extremes are needed or when computational resources are restricted [19]. The method used for downscaling is linear regression between the coarse- scale to fine-scale but when the climate large-scale and local parameters follow different probability laws non-linear such as neural networks [15], classification and regression trees [20], the analog method [21], or classification methods $[22,23]$ are used. In the case of large-scale atmospheric circulation and daily rainfall, a linear statistical regression model cannot explain appropriately the physical link between both sets of variables. It cannot undermine that the theoretical and numerical approach of nonlinear methods are difficult. In this paper, a well-known geostatistical interpolation technique known as kriging [24, 25], was selected due to the behavior of the nonlinearly with respect to the spatial coordinates because this GCM simulation uses empirical orthogonal function analysis [26, 27] such as sea pressure level in GCM which can be used to predict local parameters by interpolation or extrapolation techniques[18]. As most statistical downscaling methods (SDMs) three different techniques were tested for the first interpolation of GCM output: bilinear, bicubic and kriging. The resulting SDMs were evaluated by comparing downscaled temperature and precipitation at local sites and the impact of the interpolation technique on patterns of variability was explored. The SDM based on kriging interpolation, providing the best accuracy, was then validated on present-day data outside of the calibration period [28]. As ArcGIS geostatistical tool kriging also for statistical downscaling of temperature scenarios for the whole source of the Yellow River [29] in this study this approach is adopted to downscale EdGCM output. But the requirement of skill and complexity in application of ArcGIS for downscaling, convenient and user-friendly transform software was found to endure this kriging interpolation easily and accurately. Transform is powerful, scientific visual image software that allows big quantities of information to be viewed and analyzed graphically. It maintains a constant relationship on the screen between all kinds of graphs. It was intended to assist in analyzing two-dimensional data, which is, data with two independent variables (like latitude and longitude) and single dependent variable like temperature. This software can create a contour plot from the dataset. Transform's fill missing data command is used for downscaling through kriging interpolation. The main impact of climate change is increasing temperature which leads to severe calamities like flash flood and prolonged flood in these areas. This work aims to provide a suitable scenario for the finer-resolution Sylhet district in Bangladesh. So that the global climates change impacts can be quantified at a local scale. This study has been carried out to evaluate the performance of transform software for downscaling global climate model EdGCM outputs and observe the variation between local and downscaled data by developing an annual and seasonal trend. 


\section{Material and Methods}

\subsection{Study Area}

This research has been conducted at Sylhet district in the Sylhet division which shown in Fig. 1.

The area of Sylhet district is 3490.40 Square Kilometer having a population about $25,55,566$. It is located in between $24^{\circ} 36^{\prime}$ and $25^{\circ} 11^{\prime}$ north latitudes and in between $91^{\circ} 38^{\prime}$ and $92^{\circ} 30^{\prime}$ east longitudes [30]. The climate is classified as tropical in Sylhet. The average annual temperature is $24.8^{\circ} \mathrm{C}$ in Sylhet. August is the hottest month, with temperatures averaging $28.1^{\circ} \mathrm{C}$. At an average temperature of $18.5^{\circ} \mathrm{C}$, January is the coldest month of the year. Throughout the year, temperatures vary by $9.6^{\circ} \mathrm{C}$ [31].

\subsection{Data Collection}

Three types of data had been used for this study: (1) Global data (2) Downscaled data and (3) Observed data. Global data was derived from the Global Climate Model EdGCM. The downscaled data is the monthly surface air temperature obtained from EDGCM (Doubled $\mathrm{CO}_{2}$ simulation) over a period of 53 years (1st January 1968-31st December 2020). This model "measures" the sensitivity of the climate to a doubling of $\mathrm{CO}_{2}$. Starting with a climate of 1958 and with $\mathrm{CO}_{2}$ concentrations of $314.9 \mathrm{ppm}$, this produces an instantaneous doubling of $\mathrm{CO}_{2}$ levels to $629.8 \mathrm{ppm}$. The model then reacts to the forward-looking extra radiative forcing to 2100 . So, Doubled_ $\mathrm{CO}_{2}$ means to run equilibrium simulations with an instantaneous doubling of carbon dioxide [32]. Transform software was used for downscaling. The observed data (1st January 1968-31st December 2017) were collected from BMD (Bangladesh Meteorological Department). A continuous data set is a quantitative data set that can have values that are represented as values or fractions. Temperature is a continuous variable and due to the representation as degree Celsius, it can be termed as time interval data. The working process that has been carried out in this work can be shown in the flow diagram (Fig. S1).

\subsection{EdGCM}

EdGCM was based on certain boundary conditions (e.g., topography, vegetation, drag coefficient, radiation) which need for simulations. Time period 1968 to 2020 was used to conduct the temperature. Maximum surface air temperature was extracted according latitude and longitude.

\subsection{Downscaling by Transform Software}

Downscaling of climate change data was carried out using transform software. Transform is a program with most features that is extremely interactive. This software is capable of opening image in 2D and 3D dataset format and image can be saved in different format which is used to analyze, manipulate, visualize and organize a large amount of multi-dimensional information. Transform fill missing data was used to replace unwanted data values by estimating those data values that should be based on the evaluation of kriging. The kriging method is the most precise fill method. Downscaled temperature data was extracted for the Sylhet district according to latitude and longitude. The working process of transform software is shown in the flow diagram (Fig. S2).

\subsection{Percent of Bias (PBIAS)}

The average tendency of the simulated data to be greater or lower than their observed counterparts is defined as Percent of bias (PBIAS) [33].

$$
\operatorname{PBIAS}(\%)=\left[\frac{\sum_{i=1}^{n}\left(Y_{i}^{o b s}-Y_{i}^{s i m}\right) * 100}{\sum_{i=1}^{n}\left(Y_{i}^{o b s}\right)}\right]
$$

Where PBIAS is the deviation of data expressed as a percentage.

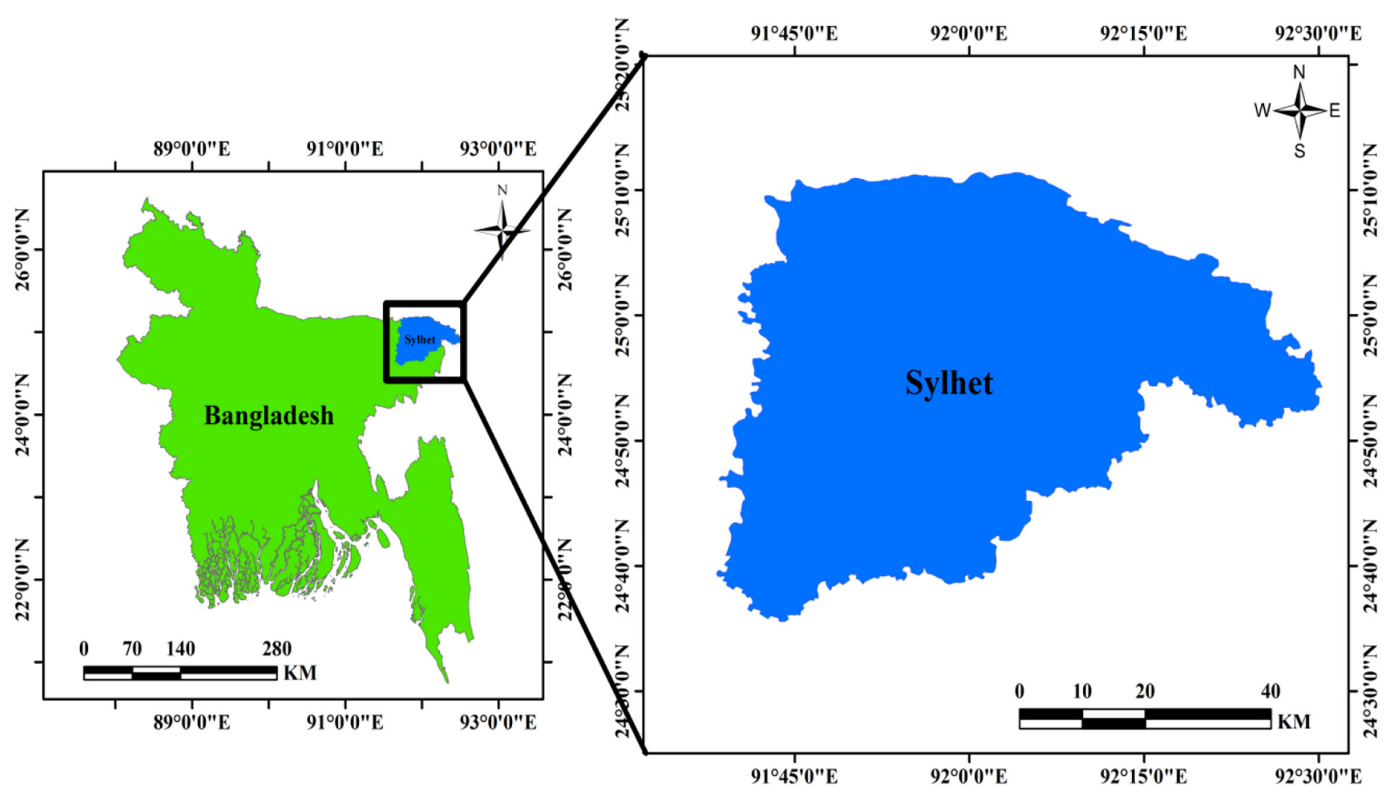

Fig. 1. Study area. 


\subsection{Nash-Sutcliffe Efficiency (NSE)}

The effectiveness of Nash-Sutcliffe (NSE) is a normalized statistic which determines the relative magnitude of the residual variance compared to the variance of measured data. NSE shows how well the observed plot versus downscaled data fits. NSE ranges from $-\infty$ and 1.0 ( 1 inclusive), the optimal value being NSE $=1$. Values between 0.0 and 1.0 are usually considered to be acceptable performance level. Values $<0.0$ shows that the mean observed value is a stronger predictor than the simulated value, which shows unacceptable output [34]. The Nash-Sutcliffe efficiency (NSE) is defined as:

$$
\mathrm{NSE}=1-\left[\frac{\sum_{i=1}^{n}\left(Y_{i}^{o b s}-Y_{i}^{S i m}\right)^{2}}{\sum_{i=1}^{n}\left(Y_{i}^{\text {obs }}-Y^{\text {mean }}\right)^{2}}\right]
$$

\subsection{Trend Analysis}

Trend analysis is used to observe trends in the time series of temperature. In the current study, Mann Kendall Test and Sen's slope estimator have been used in XLSTAT. Non-parametric Mann Kendall test is used to search a monotonic trend that increases or decreases, and the slope of the linear trend is also calculated with the nonparametric Sen's methodology [35].

\subsubsection{Mann- Kendall trend test}

Mann-Kendall trend test (Statistical test) is widely used for trend analysis. The Mann-Kendall S Statistic is computed as follows Eq. (3):

$$
S=\sum_{i=1}^{n-1} \sum_{j=i+1}^{n} \operatorname{sign} T_{j}-T_{i}
$$

$$
\text { Sign, } T_{j}-T_{i}=1 \text { if } T_{j}-T_{i}>0 \text {, }
$$

$$
0 \text { if } T_{j}-T_{i}=0 \text { and }-1 \text { if } T_{j}-T_{i}<0
$$

Where, $T_{j}-T_{i}$ are the annual values in years $j$ and $i, j>i$, respectively. A positive (negative) value of $S$ shows an upward (downward) trend.

A positive value of Sen's estimator indicates an upward or increasing trend and a negative value of Sen's estimator provides a downward or decreasing trend in the time series [36].

\section{Results and Discussion}

\subsection{Analysis of EdGCM Model for Doubled_ $\mathrm{CO}_{2}$ and Global_ Warming_ 01}

The output of the Doubled $\mathrm{CO}_{2}$ simulation for analysis of EdGCM model is shown in Fig. 2. This is the most significant characteristic of a climate model which referred to as "post-processing". For Doubled_ $\mathrm{CO}_{2}$ simulation, the run started from December 01, 1967 (one month earlier than actual time January 01, 1968) and ended on December 31, 2020. It is standard practice for the simulations to begin one month before the production of analyzable data begins. This is referred to as a period of "spin-up", during which atmospheric numerical noise subsides. This noise is linked to the fact that there is no perfect balance between the initial conditions and boundary conditions at the beginning. The noise is "ironed out" within a month and significant output starts to accumulate [37].

EdGCM allows the introduction of global maps, zonal averages, time series plots and there is a possibility to examine the facts of some climate variables. Temperature data from the scenarios are evaluated which provides a relatively good idea of what direction the world is going in climatically. Global maps display temperature variation in 1968, 1978, 1988, 1998, 2008, 2018, 2019 and 2020. The global temperature is $16.05^{\circ} \mathrm{C}$ in 1968 with a maximum of $29.90^{\circ} \mathrm{C}$ and a minimum of $-43.50^{\circ} \mathrm{C}$. Temperature is $19.41^{\circ} \mathrm{C}$ for the region of Sylhet in 1968. During (1978-2018) there is a rise in global temperature from 16.91 to $18.01^{\circ} \mathrm{C}$. In 2019 the average global temperature is $17.99^{\circ} \mathrm{C}$ and the maximum is $32.10^{\circ} \mathrm{C}$ It has been observed from the result that global temperature is $18.05^{\circ} \mathrm{C}$ in 2020 . The annual temperature is predicted to be $21.67^{\circ} \mathrm{C}$ by 2020 in Sylhet.

Higher emissions of carbon dioxide responsible for temperature rise. The rise in temperatures will produce a drastic effect on the global climate of ice cap melting and flooding close sea level. EdGCM allows diffusion of heat between the lower atmospheric and upper ocean layers. Ice cover, snow and sea surface temperature are taken consideration in this model. In the Doubled_ $\mathrm{CO}_{2}$ run for EdGCM, the global annual average decreases in snow and ice coverage was $-4.15 \%$, indicating an increase in surface air temperature of $0.044^{\circ} \mathrm{C}$. In some grid cells, the snow and ice cover decrease to $-96.6 \%$ in the EdGCM runs where local temperature response are maximum likewise much greater than global averages. The certainty or uncertainty associated with the parameterization of sea ice in EdGCM is currently unclear, and from other hydrological cycle variables it is difficult to extract snow and ice feedback [32]. Temperature difference shows how average global temperature has changed from 2010-2100. The average overall increase was 0.32 degrees with a max of 3.32 degrees and a minimum of -1.85 degrees [38].

Fig. S3 shows Global_warming_ 01 predicted global surface air temperature. According to EdGCM, in the global warming experiment, the $\mathrm{CO}_{2}$ trend involves an exponential change of $1 \%$ per year from 2000 to 2100 . The total amount of global warming at the end of this transient simulation is $4^{\circ} \mathrm{C}$ and $\mathrm{CO}_{2}$ concentration will be $900 \mathrm{ppm}$. From IPCC report a slowdown in emissions growth until late in the 21st century (ie RCP8.5), the temperatures are forecast to continue increasing and by 2100 and reach around $4^{\circ} \mathrm{C}$ higher than the late 20th century levels. Concentrations of $\mathrm{CO}_{2}$ in the atmosphere accelerate and reach $950 \mathrm{ppm}$ by 2100. Based on the $\mathrm{CO}_{2}$ trend there is a similarity between Global_ warming_ 01 with RCP 8.5 [39].

For the global, northern hemisphere and southern hemisphere the annual temperature gives a clear picture. It is seen that increases in the average temperature vary from one year to another. The global annual average temperature for the period 1968 was $13.07^{\circ} \mathrm{C}$ with a maximum of $27.06^{\circ} \mathrm{C}$. During 1978 to 2020 temperature increases from 13.16 to $13.75^{\circ} \mathrm{C}$. It is found that the maximum global temperature is expected to occur during the year 2020 which is $28.28^{\circ} \mathrm{C}$. Temperature also increases in the Sylhet area. The southern hemisphere shows a similar temperature for the period 2019 and 
Annual Surface Air Temperature (Doubled_CO2.1968-1968ij.nc)
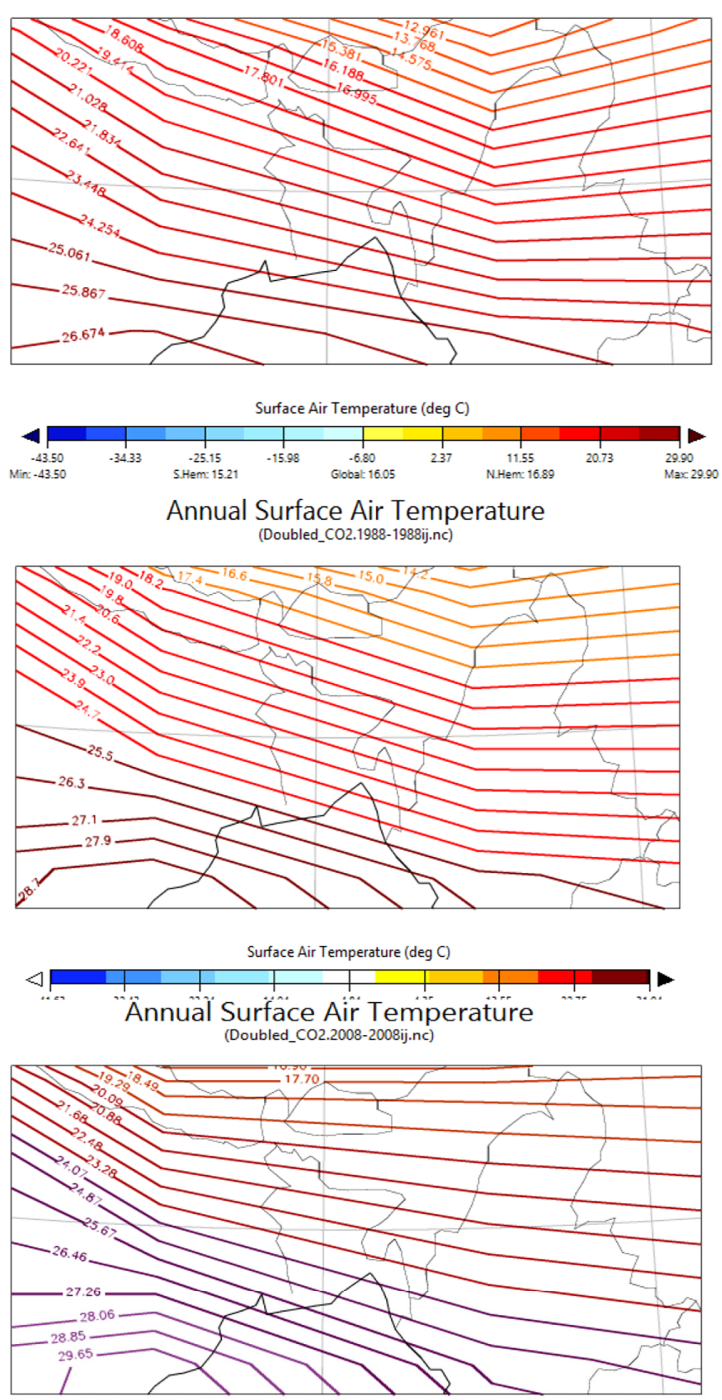

Surface Air Temperature (deg C)
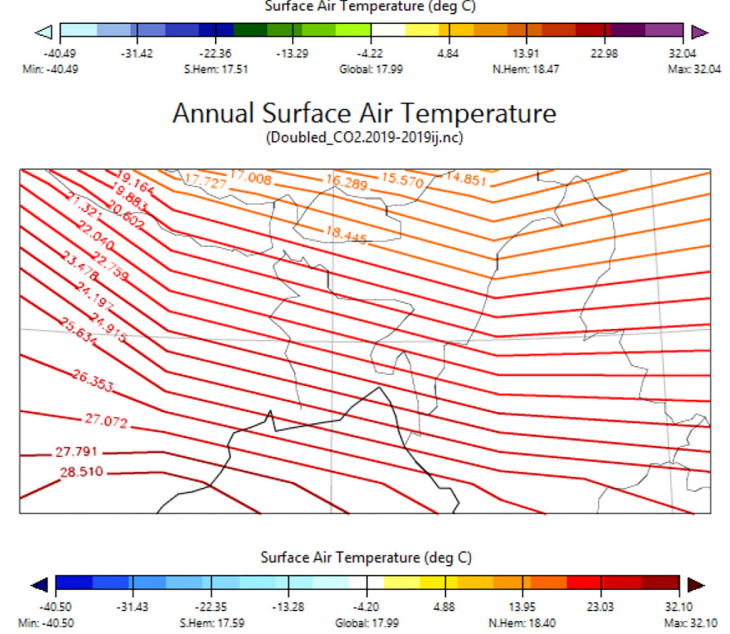

Annual Surface Air Temperature (Doubled_CO2.1978-1978j,.nc)
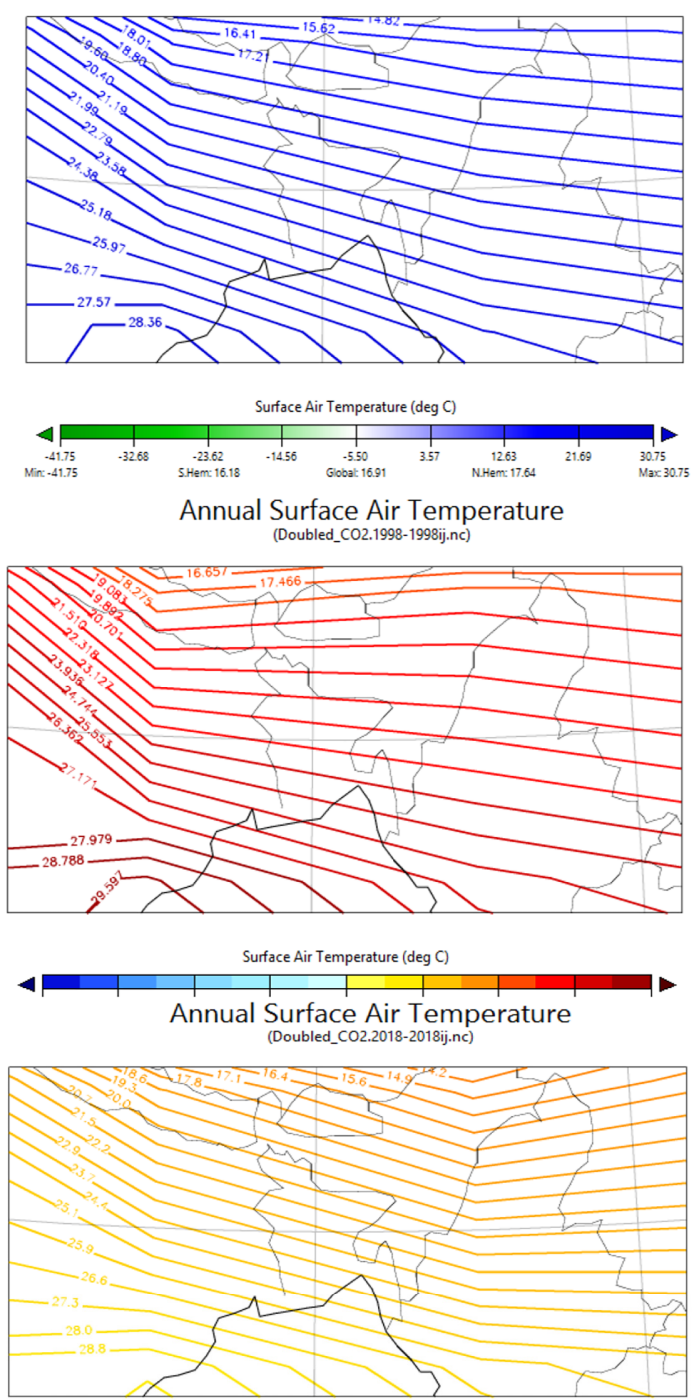

Surface Air Temperature (deg C)
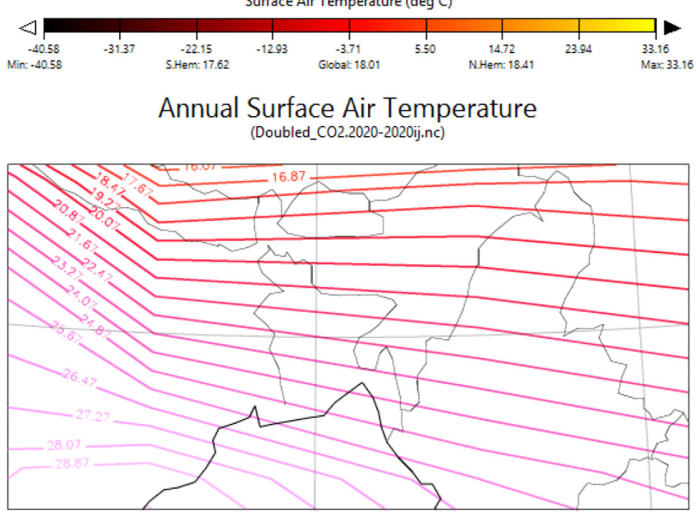

Surface Air Temperature (deg C)

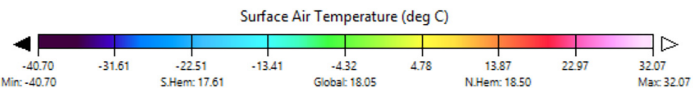

Fig. 2. Temperature change for the Doubled_ $\mathrm{CO}_{2}$ scenario. 
2020.Maximum temperature is showed by Doubled_ $\mathrm{CO}_{2}$ as compared to Global_Warming_01. So, Doubled_ $\mathrm{CO}_{2}$ data are downscaled by transform software.

\subsection{Downscaling Validation}

Outer layer data of kriging interpolation shows in Fig. 3(a) for validation. As both software ArcGIS and Transform use kriging interpolation method as it is the most convenient method of interpolation. The number of cell for EdGCM is $8^{0} \times 10^{0}$, so it considers the out-layer data for kriging interpolation. This study observed the variation in climate data of April 2017 after running ArcGIS and Transform software. Flash flood was the most hazardous incident in April 2017. A large part of the Sylhet region has been flooded in 2017. So, April 2017 was choosing to observe the variation in climate data. Fig. 3(b) and (c) show that both ArcGIS and Transform software generates the same temperature data for the study area.

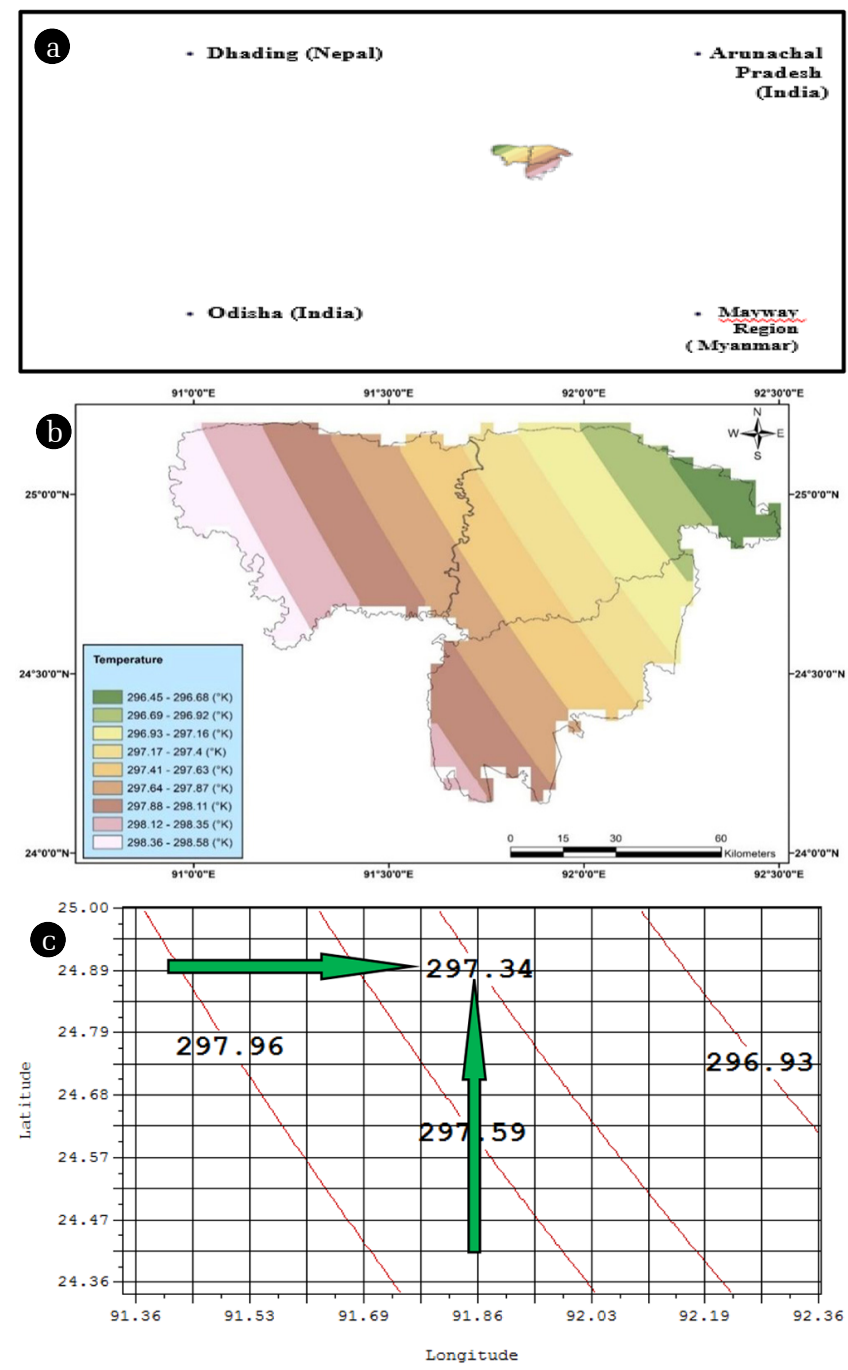

Fig. 3. Out layer data for kriging interpolation (a), variations of downscaled temperature data for ArcGIS (b) and Transform software (c).

\subsection{Monthly and Yearly Variability of Temperature}

The monthly variability of temperature is shown in Fig. S4. Standard deviation for downscaled and observed temperature is $5.834^{\circ} \mathrm{C}$ and $6.550^{\circ} \mathrm{C}$. A higher standard deviation indicates that the data is more spread out. A low standard deviation indicates that the data points tend to be very close to the mean. The mean value for downscaled temperature is $27.99^{\circ} \mathrm{C}$ and observed temperature is $31.04^{\circ} \mathrm{C}$. As standard deviation of downscaling is low it can be concluded that it can predict satisfactory. For Sylhet district, monthly trend of downscaled and observed data shows a similar type of variability which indicates a better correlation between the predictor and predictand variables. The performance of the downscaled temperature is more satisfying in monsoon season (June-September) for period 1968-2017. For the month January, April, November, and December the downscaled does not show well performance.

A study was carried out to identify the large-scale atmospheric variables as predictors for statistical downscaling of daily rainfall, maximum and minimum temperatures in Bangladesh. Nine stations were selected to demarcate the climatic domain. Sylhet station is one of them and temperature records for the climatic base years (1961-2000) are available. Daily mean temperature is $24.8^{\circ} \mathrm{C}$ for Sylhet station. Surface meridional velocity, relative humidity at $850 \mathrm{hPa}$, meridional velocity at $850 \mathrm{hPa}$, and geopotential height at $500 \mathrm{hPa}$ are the major controlling parameters for both the daily maximum and minimum temperatures in Bangladesh [40].

Yearly variability of temperature is shown Fig. 4. It represents the trend analysis between IPCC and Downscaled temperature. The rate of change is defined by the slope of regression using a linear regression model, which is about $0.0165^{\circ} \mathrm{C} /$ year for downscaled and $0.00543^{\circ} \mathrm{C} /$ year for IPCC during the period of 2006-2020. Coefficient of determination $\left(R^{2}\right)$ is higher in downscaled temperature than IPCC. Using CGCM3A2 and RCP 4.5 the maximum temperatures increases from $0.03^{\circ} \mathrm{C}-0.21^{\circ} \mathrm{C}$ in 2020 [41].

\subsection{Annual Temperature Trend Analysis and Scatter Plot}

The results of annual temperature trend analysis are shown in Fig. S5. Time series visualization is used to determine whether an abrupt increase or decrease in mean annual temperature. The downscaled data are analyzed for the period (1968-2020) and observed data for the period (1968-2017). It is clear that the observed trend is significantly positive because the average annual temperature is increased gradually. Therefore, it seems that the downscaled annual average temperature is also increased gradually but sudden decreases occur after 2002 and further increases from 2004.

From 1958 to 2010, the temperature has an increasing trend but exponential decrease begins right in 2010. A decreasing temperature trend is not seen until 2018. The global average temperature drops dramatically between 2010 and 2100, with a global average of -0.86 degrees. The temperature is higher at certain points in the 2020-2040 decade than it was in 2010 [38].

Fig. 5 shows the scatter plot for downscaled, observed and IPCC temperature. Mann-Kendall Z tests for annual downscaled and IPCC during (2006-2020) show a positive trend. For downscaled temperature $Z=2.77$ and Sen's slope 0.186 which means the 


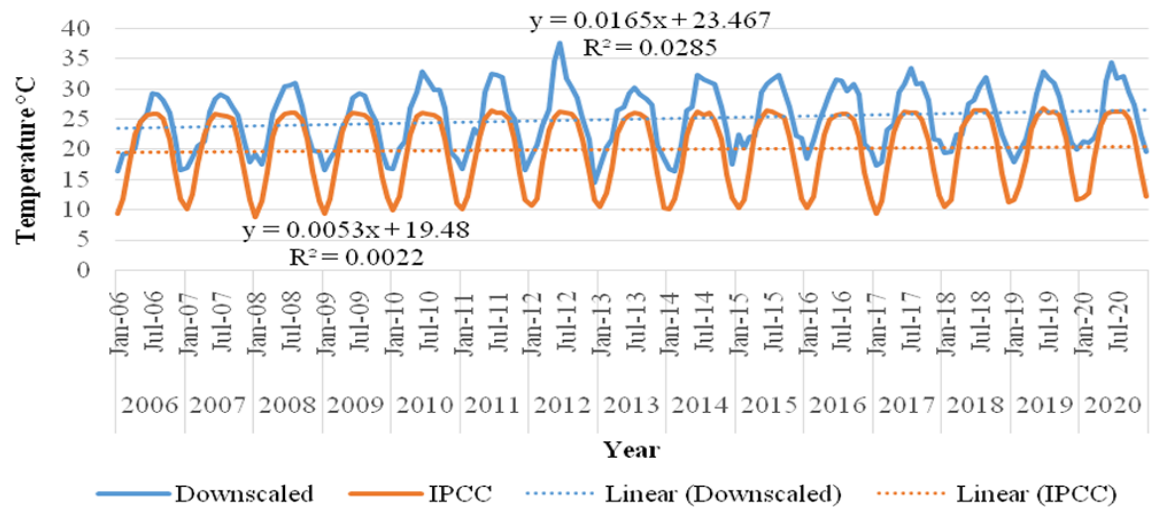

Fig. 4. Yearly predicted temperature for downscaled and IPCC temperature.
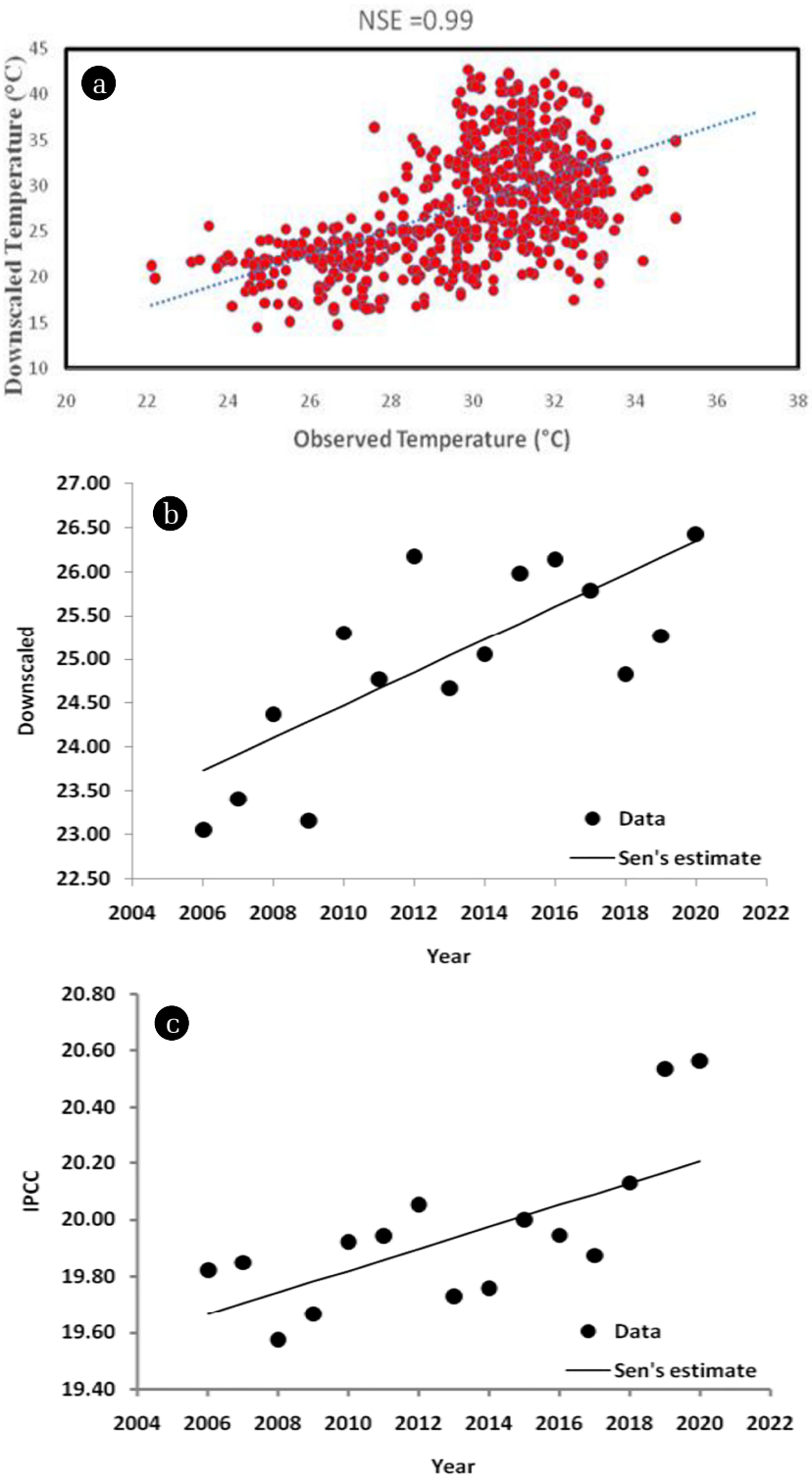

Fig. 5. Scatter plot for downscaled, observed and IPCC temperature. trend is increasing significantly. For IPCC $Z=2.97$ and Sen's slope 0.039 which is also increasing significantly. PBAIS for monthly average temperature of Sylhet station is $6.05 \%$ which is slight underestimation of downscaled temperature.

Daily observed temperature and rainfall data from 1981 to 2006 was used to conduct the calibration and 2007 to 2011 was used for validation using SDSM. PBIAS for maximum temperature of Sylhet station and minimum temperature of Sylhet station are $-0.30 \%$ and $-0.47 \%$, respectively. So, downscaled temperature is slightly overestimated. NSE for maximum temperature of Sylhet station and minimum temperature of Sylhet station are 0.80 and 0.79 respectively [42]. NSE for Sylhet station is 0.99 which means downscaled temperature value is a better predictor than mean observed value i.e. acceptable performance. RSR value is $2.94 \times$ $10^{-7}$ i.e. model downscaling performance is very good as [34].

\subsection{Mann-Kendall Trend Test for Downscaled and Observed Temperature}

Fig. 6 shows Mann-Kendall trend for downscaled and observed temperature. Downscaled maximum temperature is $42.71^{\circ} \mathrm{C}$ for the period (1968-2020). It is true that the observed monthly mean temperature change is significant in the study area.

Mann-Kendall test for downscaled and observed temperature is presented in Table 1. As the computed $p$-value, which is computed using an exact method, is lower than the significance level alpha $=0.05$, one should reject the null hypothesis, and accept the alternative hypothesis.The Kendall's tau rank correlation coefficient is determined to show the sign of the relationship between time and the variables. Tau is first tested by the two-tailed test. Based

Table 1. Mann-Kendall Trend Test for Downscaled and Observed Temperature $\left({ }^{\circ} \mathrm{C}\right)$

\begin{tabular}{lcc}
\hline Variable & $\begin{array}{c}\text { Downscaled } \\
\text { temperature }\left({ }^{\circ} \mathbf{C}\right)\end{array}$ & $\begin{array}{c}\text { Observed temperature } \\
\left({ }^{\circ} \mathbf{C}\right)\end{array}$ \\
\hline Kendall's tau & -0.163 & 0.203 \\
$S$ & -32923.000 & 36272.000 \\
$P$-value & $<0.0001$ & $<0.0001$ \\
Alpha & 0.05 & 0.05 \\
Sen's slope & -0.0002 & 0.0001 \\
\hline
\end{tabular}



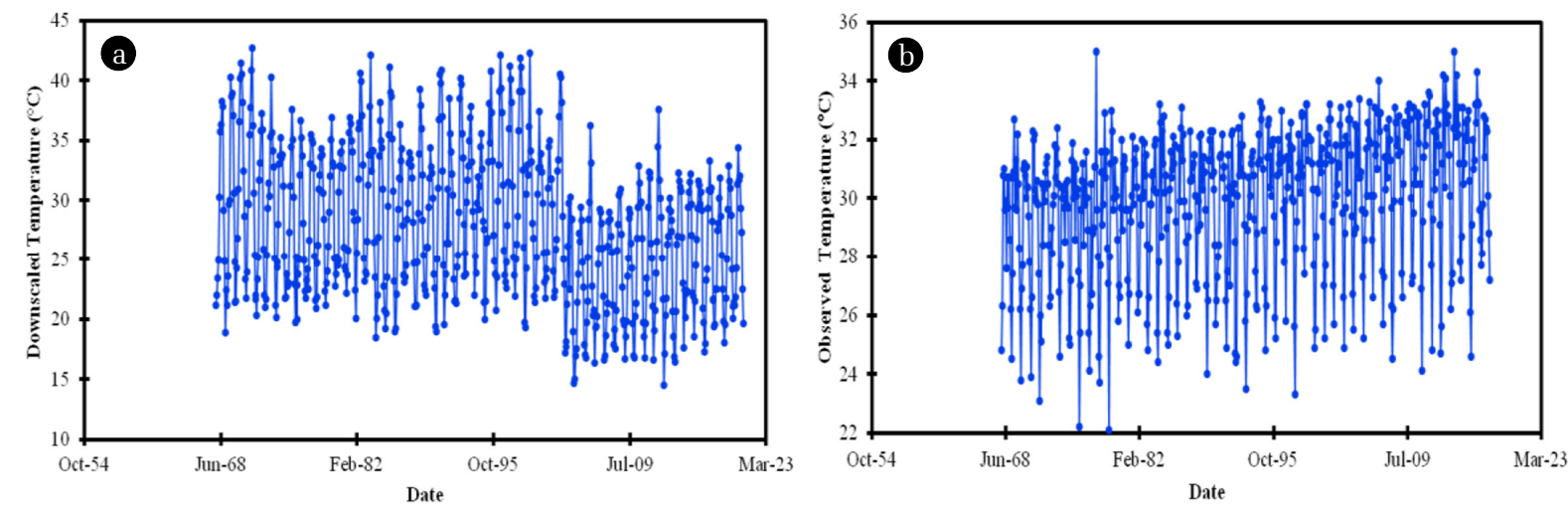

Fig. 6. Downscaled and observed monthly mean temperature.
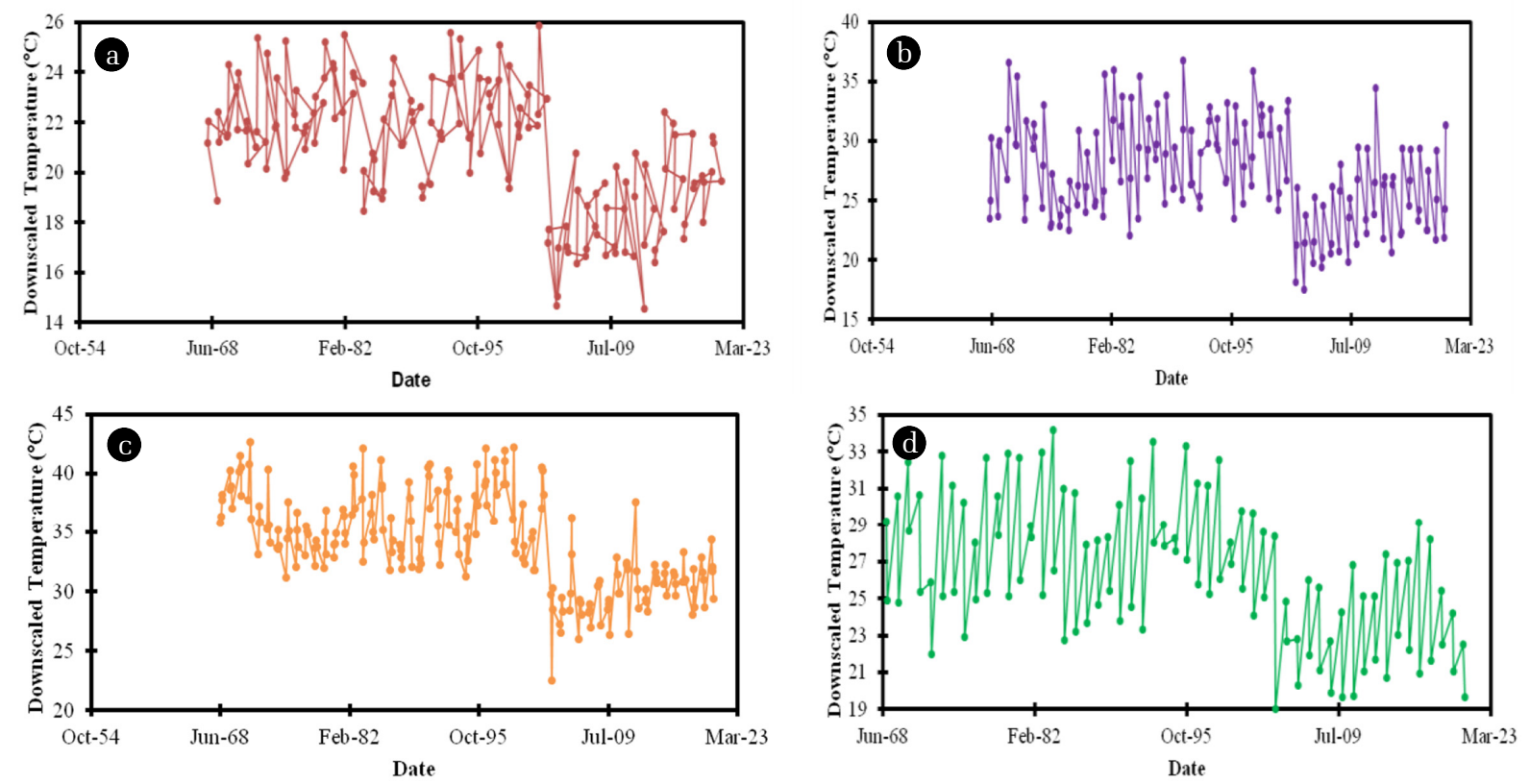

Fig. 7. Seasonal Mann-Kendall test of downscaled temperature for winter, pre-monsoon, monsoon, post-monsoon season.

on Kendall's tau $(\tau)$, the Mann-Kendall trend test is used to detect monotonic trends in the time series. The two-tailed Mann-Kendall test gives a significant result for both downscaled and observed temperature with the results for the tests of Kendall's tau. Value of $S$ shows (positive) upward and (negative) downward trend.

\subsection{Seasonal Mann-Kendall test of Downscaled and Observed Temperature}

Seasonal Mann-Kendall trend for downscaled temperature is indicated in Fig. 7. The temperature trend is found for winter (Dec-Feb), pre-monsoon (Mar-May), monsoon (Jun-Sep) and post-monsoon (Oct-Nov).

Mann-Kendall test results for downscaled temperature according to seasonal are presented in Table S1. Downscaled temperature patterns for durations (1968-2020) denote significant negative trend at $95 \%$ confidence level. Downscaled monthly mean temperature in the winter season for Sylhet districts is significantly decreasing with Sen's slope-0.084.

Fig. S6 shows seasonal Mann-Kendall trend for observed temperature.

Seasonal Mann-Kendall test results for observed temperature are presented in Table S2. Observed temperature patterns for periods (1968-2017) show significant positive trends at 95\% confidence level for all seasons. Observed monthly mean temperature in the winter season for Sylhet districts is significantly increasing with positive Sen's slope 0.037 .

\section{Conclusions}

Climate change vulnerability can be minimized if proper trend of temperature will generate by considering global climate model simulations. EdGCM is a numerical method which provides almost accurate result in less time and easy way. Statistical downscaling 
is more reliable, computationally inexpensive and most appropriate if time and financial resources are limited. By using transform, it is easy to conduct geostatistical downscaling than physical. These points have determined to some extent the selection of statistical downscaling strategies in this study. Moreover in this region, there are few stations, so it is a better to use this new approach for downscaling. EdGCM output scenario combination of Doubled_ $\mathrm{CO}_{2}$ and Global_Warming_01 can efficiently produce data on a global scale. Here, the kriging method was used to produce the missing data. Mean monthly temperature indicates a better correlation between the predictor and predictand variables for the period (1968-2017). The downscaled and observed values are more matching in monsoon season (June -September). During (2006-2020) the temperature changes is about $0.0165^{\circ} \mathrm{C} /$ year for downscaled and $0.00543^{\circ} \mathrm{C} /$ year for IPCC. Mann-Kendall $\mathrm{Z}$ tests for annual downscaled and IPCC during (2006-2020) show a positive trend. For downscaled temperature $Z=2.77$ and sen's slope 0.186 which means the trend is increasing significantly. For IPCC $Z=2.97$ and sen's slope 0.039 which is also increasing significantly. Downscaled annual temperature is also increased from starting period but it decreases after 2002 and further increases from 2004. Observed and downscaled average annual temperatures are changed by a factor of 0.054 and - 0.1077 degree Celsius. PBIAS of the downscaled temperature data are slightly underestimated of $6.05 \%$. NSE and RAS values are 0.99 and $2.94 \times 10^{-7}$. So the downscaled temperature is fitted well to the observed one. By Mann-Kendall trend test temperature changes are significant for both downscaled and observed results of $p$-value is less than alpha $=0.05$. The study could have been far more extensive if more other scenarios of EdGCM data were used.

\section{Author contributions}

F.I. (Assistant Professor) wrote and revised the manuscript. I.J.R. (MS student) conducted all the experiments and wrote the manuscript. M.A.H. (Professor) wrote and revised the manuscript. M.A.R.S. (Assistant Professor) revised the manuscript. G.T.U. (MS student) conducted the experiments. M.H.R. (MS student) conducted the experiments. J.B. (MS student) conducted the experiments.

\section{References}

1. Binesh N, Niksokhan MH, Sarang A. Temperature Trend Analysis in Kan Watershed during Two Recent Decades. Moj. Civ. Eng. 2017;3:00063.

2. Azad S. Comparison of statistical downscaling techniques for development of future climate change scenarios for the coastal areas of Bangladesh. Dhaka: Bangladesh University of Engineering and Technology; 2015.

3. Sazal MIH. Impact of climate on the agricultural production of sylhet sadar upazila: A microclimatic study. Sylhet: Shahjalal University of Science and Technology; 2017.

4. Saadat AHM, Islam MR, Rahman SH. Introducing Educational
Global Climate Model (EdGCM) for improving education and research in climate change: Bangladesh perspective. Bangladesh J. Environ. Res. 2012;10:31-42.

5. Chandler MA, Sohl LE, Zhou J, Sieber R. EdGCM: Research tools for training the climate change generation. In AGU Fall Meeting Abstracts. 2011.

6. Hansen J, Russell G, Rind D, et al. Efficient Three-Dimensional Global Models for Climate Studies: Models I and II. Mon. Weather Rev. 1983;111:609-662.

7. Chandler M, Sohl L, Mankoff K. NASA climate modeling and data applications workshop, Goddard Institute for Space Studies, New York; 2001. P. 7-12.

8. Sornmee P, Sukawat D. Performence of forecasting model for average surface air temperature prediction over Southeast Asia. Southeast Asian J. Sci. 2014;3:1-12.

9. Surawut, Ch, Sukawat D. A Dynamic Equation for Downscaling Surface Air Temperature. Future 2015;3:5.

10. Hassan I, Ghumman AR, Hashmi HN, et al. Impact of environmental changes and global warming on temperature in Pakistan. Mehran Univ. Res. J. Eng. Technol. 2011;30:1-4.

11. Hassan I, Ghumman AR, Hashmi HN. Global warming and temperature changes for Saudi Arabia. J. Biodivers. Environ. Sci. 2016;8:179-191.

12. Pharasi S. Development of statistical Downscaling methods for the daily Precipitation process at a local Site. Montreal: McGill University; 2006.

13. Weli VE, Nwagbara MO, Ozabor F. The Minimum and Maximum Temperature Forecast Using Statistical Downscaling Techniques for Port-Harcourt Metropolis, Nigeria. Atmos. Clim. Sci. 2017;7: 424-435.

14. Rajan S. Statistical downscaling of gcm output, hydrological simulation and generation of future scenario using variable infiltration capacity (vic) model for the ganga basin, India. Uttarakhand: Andhra University; 2014.

15. Hewitson BC, Crane RG. Climate downscaling: Techniques and application. Clim. Res. 1996;7:85-95.

16. Wilby RL, Wigley TML. Downscaling general circulation model output: A review of methods and limitations. Prog. Phys. Geogr. 1997;21:530-548.

17. Biau G, Zorita E, von Storch H, Wackernagel H. Estimation of precipitation by kriging in the EOF space of the sea level pressure field. J. Clim. 1999;12:1070-1085.

18. Li Y, Yan X. Statistical downscaling of monthly mean temperature for Kazakhstan in Central Asia. Clim. Res. 2017;72:101-110.

19. Trzaska S, Schnarr E. A review of downscaling for climate change projections. States Agency for International Development by Tetra Tech ARD. 2014;1-42.

20. Hughes J, Lettenmaier D, Guttorp P. A stochastic approach for assessing the effect of changes in regional circulation patterns on local precipitation. Water Resour. Res. 1993;29:3303-3315.

21. Zorita E, Hugues JP, Lettenmaier DP, von Storch H. Stochastic characterization of regional patterns for climate model diagnosis and estimation of local precipitation. J. Clim. 1995;8:1023-1042.

22. Hulme M, Briffal KR, Jones PD, Senior CA. Validation of GCM control simulations using indices of daily airflow types over the British Isles. Clim. Dyn. 1993;9:95-105.

23. Bardossy A, Plate EJ. Space-time model for daily rainfall using 
atmospheric circulation patterns. Water Resour. Res. 1992;8: 1247-1259.

24. Chauvet P. Aide-mémoire de géostatistique linéaire. Ecole des Mines de Paris, Cahiers de Géostatistique, Fasc. 2; 1994; p. 210

25. Wackernagel H. Multivariate Geostatistics. Springer-Verlag. 1995. p.256.

26. Mardia KV, Kent JT, Bibby JM. Multivariate Analysis. Academic Press; 1979. p. 51.

27. Saporta G. Probabilités, Analyse des Données et Statistique. Editions Technip; 1990. p.493.

28. Latombe G, Burke A, Vrac M, et al. Comparison of spatial downscaling methods of general circulation model results to study climate variability during the Last Glacial Maximum. Geosci. Model Dev. 2018;11:2563-2579.

29. Zhao FF, Xu ZX. Statistical downscaling of future temperature change in source of the Yellow River Basin. Plateau Meteorol. 2008;27:153-161.

30. Banglapedia. Sylhet, 2015 [Internet]. Banglapedia; c2018. [Cited 10 December 2018]. Available from: http://en.banglapedia. org/index.php?title=Sylhet_District

31. Climate data for cities worldwide. Climate-Data.org. Climate data for cities worldwide; c2018. [Cited 10 december 2018]. Available from: https:/en.climate-data.org/

32. Kelly M. A survey of climate sensitivity and response rates in EdGCM. Carlisle PA: Dickinson College; 2011.

33. Gupta HV, Sorooshian S, Yapo PO. Status of automatic calibration for hydrologic models: Comparison with multilevel expert calibration. J. Hydrol. Eng. 1999;4:135-143.

34. Moriasi DN, Arnold JG, Van Liew MW, Bingner RL, Harmel $\mathrm{RD}$, Veith TL. Model evaluation guidelines for systematic quantification of accuracy in watershed simulations. T. ASABE. 2007;50:885-900.

35. Sen PK. Estimates of the regression coefficient based on Kendall's tau. J. Am. Stat. Assoc.1968;63:1379-1389.

36. Karmeshu N. Trend Detection in Annual Temperature \& Precipitation using the MannKendall Test - A Case Study to Assess Climate Change on Select States in the Northeastern United States. United States: University of Pennsylvania; 2012.

37. Chandler MA, Marti A, Sohl L. Global Climate Modeling Workshop. Teacher Research Academies, Lawrence Livermore National Laboratory; 7-8 July 2010.

38. Mohan A, Pecora K. Modeling climate change and testing EdGCM effectiveness. Carlisle, PA, USA: Dickinson College; 2011.

39. Riahi K, Rao S, Krey V, et al. RCP 8.5- A scenario of comparatively high greenhouse gas emissions. Clim. Change 2011;109:33.

40. Alamgir M, Pour SH, Mohsenipour M, Hasan MM, Ismail T. Predictors and their domain for statistical downscaling of climate in Bangladesh. J. Teknol. 2016;78:6-12.

41. Feyissa G, Zeleke G, Bewket W, Gebremariam E. Downscaling of future temperature and precipitation extremes in Addis Ababa under climate change. Climate 2018;6:58.

42. Nury AH, Alam MJB. Performance study of global circulation model HADCM3 using SDSM for temperature and rainfall in North-Eastern Bangladesh. J. Sci. Res. 2014;6:87-96. 